\title{
REVIEW
}

\section{A Review of Entrustable Professional Activities in Pharmacy Education}

\author{
Carmen Abeyaratne, BPharm, Kirsten Galbraith, BPharm, MClinPharm \\ Monash University, Faculty of Pharmacy and Pharmaceutical Sciences, Parkville, Australia \\ Corresponding Author: Carmen Abeyaratne, Monash University, Faculty of Pharmacy and Pharmaceutical Sciences, 381 Royal \\ Parade, Parkville VIC 3052, Australia. Tel: 613 99039163. Email: carmen.abeyaratne@ monash.edu
}

Submitted August 28, 2021; accepted December 13, 2021; ePublished December 2021

Objective. To review the published literature describing how entrustable professional activities (EPAs) are currently utilised in health professional education with a focus on pharmacy education.

Findings. An English-language CINAHL Plus and MEDLINE search was conducted for January 2011 through March 2021. 21 publications were identified for inclusion in this review. The following themes were identified: frameworks for the development of EPAs, implementation and evaluation of EPAs for workplace learning and gaps in knowledge and future directions for EPAs.

Summary. A standardised approach to development of EPA frameworks for health disciplines has yet to be established. Implementation and evaluation of EPAs as an educational tool in the practice setting is also inconsistent. An opportunity exists to further establish the development, implementation and evaluation of EPAs in all clinical practice settings. EPAs are relatively new in pharmacy practice settings and much can be learned from other health professions to ensure successful translation of EPAs into pharmacy education.

Keywords: entrustable professional activities, competency-based education, pharmacy student, medical education, pharmacist

\section{INTRODUCTION}

In 2007, the concept of entrustable professional activities (EPAs) in medical education was introduced to address the gap between educational theory and clinical practice. ${ }^{1}$ The introduction of EPAs was in response to increased awareness of educational knowledge about workplace-based learning. ${ }^{2}$ EPAs are an observable method of assessment in the workplace and translate competencies into clinical practice. ${ }^{2,3}$ An EPA incorporates one or more core competencies that are observable and measurable and can be entrusted to the learner to perform at different levels of supervision as they gain competence. ${ }^{3,4}$ The intention is for the learner to progress to each milestone and reach a level where the task can be performed independently and the learner is able to supervise more junior staff performing this task. ${ }^{3}$

EPAs are gaining attention around the world as a practical method to assess competencies in clinical practice. ${ }^{5,6}$ Implementation of EPAs has been demonstrated in several countries and health disciplines, however a standardised approach to the development of an EPA framework has not been established and has been identified as a priority for researchers. ${ }^{4,5}$ Ideally, an EPA framework should consist of a set of support documents or templates that provide guidance to researchers and educators when developing the EPA statements. ${ }^{7}$ Development of an EPA framework also relies on educational institutions and workplace requirements aligning. ${ }^{2}$ One study reports that adaptive workplaces and quality trained organisations have demonstrated successful development of an EPA framework. ${ }^{2}$ To further strengthen designed EPA frameworks it has been suggested that future researchers use a published tool, such as the EQual rubric or Quality of Entrustable Professional Activities (QUEPA) tool to determine the quality and structure of EPAs. ${ }^{4,8,9}$

The concept of EPAs is relatively recent in pharmacy education; literature to date has focused on the development of EPA statements, mapping EPAs to program and accreditation requirements, validation of EPA assessment tools and pharmacy preceptors and learners perceptions and experiences of using EPAs in the workplace setting. ${ }^{10-12}$ There is a clear need for further evaluation of EPAs that have been implemented in the pharmacy practice setting including consideration of their feasibility, practicality and whether this form of assessment is appropriate to support student learning.

\section{Objective}

The objective of this review is to describe how entrustable professional activities (EPAs) are currently utilised in health professional education with a focus on pharmacy education.

\section{METHODS}


An English-language CINAHL Plus and MEDLINE search was conducted for January 2011 through March 2021 using the following search terms alone or in combination: entrustable professional activities, pharmacist, competency-based education, medical education and pharmacy education. A search in the ERIC database was also conducted however, no additional relevant articles were found. One author (CA) conducted the database searches, screened abstracts and reviewed all the articles included in the review. Articles were included from medicine, nursing and pharmacy. Methodological quality was assessed using the Johanna Briggs Institute (JBI) checklist for systematic reviews, JBI checklist for text and opinion and Critical Appraisal Skills Programme (CASP) Qualitative checklist. ${ }^{13-15}$ The proposed framework for narrative reviews by Ferrari was used to guide the preparation of the review. ${ }^{16}$

\section{RESULTS}

Twenty-one articles were identified for inclusion in the review. Three themes were identified in this review: frameworks for the development of EPAs, implementation and evaluation of EPAs for workplace learning and gaps in knowledge and future directions for EPAs. The inclusion and exclusion of literature is described in Figure 1. 181 articles were excluded because they involved specialised medical fields and were not pertinent to the review question.

\section{Frameworks for the development of EPAs}

Eight articles relating to the development of EPA frameworks were identified for inclusion (Table 1). Three articles were descriptive in nature and five were analytical studies. ${ }^{8,17-23}$ The majority of the articles about frameworks for the development of EPAs for the workplace were in the setting of medical education. The two validated tools identified to assist in the development of EPAs are the QUEPA tool and EQual rubric. ${ }^{8,9}$

Pittenger and colleagues describe the process of developing an EPA framework that suits the pharmacy practice context while adhering to the principles outlined by ten Cate for medical education as closely as possible. ${ }^{17}$ Pittenger also highlights the importance of EPAs aligning with competencies for the pharmacy profession and of preceptor development sessions to explain the purpose of EPAs and how to use the framework; this approach is also supported by other authors. ${ }^{17-19}$ Kanmaz and colleagues also describe how an EPA task force successfully mapped all 15 core EPA statements developed by the American Association of Colleges of Pharmacy (AACP) for pharmacy graduates in 2017 to the five educational guidance documents that govern the Doctor of Pharmacy (PharmD) curriculum in America ${ }^{21}$ In another study, Pittenger and colleagues developed a questionnaire looking at pharmacy students' perceptions of EPAs, based on the validated QUEPA tool and demonstrated $>94 \%$ of students agreed that 14 out of the 15 EPA statements published by the AACP were relevant to pharmacy practice. ${ }^{23}$ Haines and colleagues also used the QUEPA tool surveying pharmacists instead of students..$^{19}$ In this study there was consistently high agreement (>75\%) among experienced pharmacy practitioners that the 15 EPAs developed by the AACP were important to pharmacy practice and set a clear expectation of what pharmacists are expected to do regardless of practice setting. ${ }^{19}$ A significant amount of work has been completed around the development and validation of the 15 core EPAs for new pharmacy graduates, published by the AACP in 2017, however there is limited published evidence about the integration of these EPAs in the clinical setting to support workplace-based learning. ${ }^{10}$

Further guidance has been provided around the development of EPA frameworks with researchers developing and validating a scoring rubric with descriptive anchors to evaluate EPAs. ${ }^{8}$ Taylor and colleagues developed the EQual rubric as a reliable measure for the quality and structure of EPAs and provided guidance for directing revisions. The EQual rubric was developed for medical education however, can also assist with validation studies for researchers developing EPAs in other health profession fields. ${ }^{8}$ Meyer and colleagues applied the EQual rubric questionnaire to 13 core EPAs developed by the Association of American Medical Colleges (AAMC) for entering medical residency. ${ }^{20}$ Nine of the 13 EPAs scored above the overall cut-off score for validation indicating alignment with the key domains for EPA design. ${ }^{20}$ The EQual tool is useful at identifying which EPAs need to undertake further revisions to ensure they are ready for use by supervisors and learners in the workplace. Further, the authors state that EPA development requires determined standards and thus a criterion based evaluation is appropriate. ${ }^{8}$ This is in contrast to the QUEPA tool, which uses a normative scale for each question without descriptive anchors. ${ }^{8}$

An exploratory qualitative study of trainers and trainees in the Dutch GP training programme explored and reported their thoughts, views and expectations about an EPA framework. ${ }^{22}$ Advantages identified through the focus group included trainers and trainees felt the EPAs provided a broad and structured overview of training required for general practice and the EPAs reflected situations and tasks commonly encountered in daily clinical practice. Disadvantages included trainers and trainees felt there were too many EPAs, some EPAs were very general making them unsuitable for formal assessment and fear the "long list of EPAs may lead to a situation in which this is used as a checklist, rather than as a supportive educational tool." ${ }^{22}$ Trainers and trainees both indicated that EPAs can support trainee learning in several aspects of the learning process including understanding training requirements, providing feedback on current performance and feed forward strategies to further progress trainee skill development. ${ }^{22}$ 


\section{Implementation and evaluation of EPAs for workplace learning}

Eleven articles pertaining to implementation and evaluation of EPAs to support workplace learning were identified for inclusion (Table 2). Four articles were descriptive in nature and seven were analytical studies. ${ }^{2,10,12,24-31}$ Many articles detail the challenges of implementation of EPAs in the workplace. ${ }^{2,29,30}$ In the context of medical education, van Loon and colleagues suggest that successful implementation of EPAs should include both the learners (medical residents) and program directors having a clear understanding of the resident's progress in training, workplace creativity to fulfil any remaining needs for training and the training program being flexible. It also suggests that for successful implementation of EPAs the workplace must be flexible and willing to change and faculty development programs must focus on EPAs. ${ }^{2}$ Jarrett and colleagues describe the potential benefits of implementation of the 15 core EPAs published by the AACP into practice for PharmD students. ${ }^{29}$ A challenge to implementation they consider is translating EPAs to a traditional grading system. The AACP recommends PharmD students achieve entrustment level 3 (reactive supervision) for each EPA upon graduation. ${ }^{29}$ This sets the expectation for student performance upon graduation but offers little guidance about how students achieve milestones as they progress through their course of study. ${ }^{29}$ The authors suggest regular progress checkpoints for assessing student progression by working backwards from graduation to the first year of study. ${ }^{29}$ They also consider the potential of EPA personalisation to specific practice environments. For example, an EPA for establishing a new patient care service could be developed for a student pursuing pharmacy ownership. ${ }^{29}$

A cross- sectional survey conducted by Jarrett and colleagues evaluated implementation of EPAs in a medical residency program. ${ }^{28}$ The survey of 503 program directors showed $90.1 \%$ were aware of EPAs as an assessment for residents, $82.8 \%$ reported understanding the principles of EPAs as an assessment, however only $30.2 \%$ reported being extremely confident in utilising EPAs. The largest challenges identified were difficulty in integrating EPAs into the current assessment program and lack of faculty development regarding EPAs. ${ }^{28}$

Rhodes and colleagues conducted a pharmacy student self-assessment and preceptor-student assessment of EPA levels during a pharmacy practice 2 -month experience. ${ }^{12}$ Student-self and preceptor-student evaluations at the midpoint and final reported a median EPA level of 3.0 and 4.0 respectively. This study demonstrated that EPA statements can be implemented into pharmacy education and can be used to assess a learner's level of performance on core pharmacy practice activities. ${ }^{12}$ In a retrospective review Sjoquist and colleagues investigated and evaluated openended feedback from preceptors to student pharmacists regarding their performance on EPAs during a pharmacy practice placement. ${ }^{10}$ The authors concluded that subjective, preceptor provided feedback can assist in identifying the strengths and challenges influencing student pharmacists' progression and understanding the learners ability during a practice experience. ${ }^{10} \mathrm{~A}$ limitation in both these studies is the EPA statements were developed for their respective institutions for pharmacy students thus differed from those published by the AACP for pharmacy graduates. ${ }^{10,12}$

Currently, literature in pharmacy education has yet to fully explore the implementation experience and effectiveness of EPAs for workplace learning for pharmacy graduates. ${ }^{10}$ However, Westein and colleagues describe the development, implementation and evaluation of EPAs for community pharmacy trainees in the Netherlands. ${ }^{27}$ The authors highlight using design approaches from the medical field to develop the EPAs, similar to methodologies reported in other pharmacy education studies. ${ }^{17,19}$ Focus groups following implementation in this community pharmacy cohort reported a heavy workload, insufficient insight into what is expected of both trainees and supervisors within the curriculum, and challenges with using the assessment tools and portfolio. ${ }^{27}$ The authors conclude that further evaluation around whether the educational environment in community pharmacies is suitable to support and encourage the learning and performance of trainees is needed. ${ }^{27}$

In an exploratory qualitative study Lau and colleagues described the perceptions and experiences of using new EPAs in nursing students, hospital and university clinical instructors. ${ }^{25}$ The EPAs allowed flexible assessment methods, fostered student's critical thinking, promoted team based care and encouraged peer teaching. ${ }^{25}$ However, EPA assessment accuracy was impacted by multiple competencies for the EPAs, subjective assessment criteria, lack of standardisation using checklists, and staff availability. ${ }^{25}$ The authors concluded that implementation of EPAs in nursing education is an evolving process and further refining is needed to adapt the EPAs to improve the learning experience. $^{25}$

Martin and colleagues conducted focus groups to understand how EPAs and entrustment scales influenced feedback and learning in the clinical setting for medical trainees. ${ }^{24}$ The authors concluded that EPAs need to be standardised to support learning but also comprehensive and flexible. ${ }^{24}$ They also found that while EPAs can support goal setting and learning for trainees they pose a risk of becoming a checklist exercise. ${ }^{24}$ Finally, the authors also conclude that reducing emphasis on the entrustment score and focusing on constructive feedback and discussion for skill progression may provide a more supportive environment to assist learning. ${ }^{24}$

As a strategy to enhance implementation of EPAs ten Cate and colleagues explored the use of an electronic portfolio (e-portfolio) model to be used for assessment and entrustment. ${ }^{30} 36$ students participated in a 12-week pilot of EPAs within the existing curriculum, using an e-portfolio specifically designed to support the EPA-based 
curriculum. ${ }^{30}$ This study has yet to evaluate the EPAs in practice but concluded incorporation of the EPAs and the use of e-portfolios requires substantial explanation and guidance. ${ }^{30}$

Two additional small studies evaluated the feasibility of EPAs introduced to the workplace for medical education. ${ }^{26,31}$ A program feasibility evaluation piloted two EPAs in an internal medicine residency program. Attendings felt that the EPAs were useful for learning and feedback, however barriers included time demands and challenges in informing all staff in the program about a new form of assessment. Interns felt that the work culture meant they needed to prioritise immediate work duties over EPAs and medical attendings struggled to find time together with the intern to observe the EPA and complete the EPA rubric. ${ }^{31}$ Baer and colleagues assessed the feasibility and satisfaction of using EPAs for physical medicine and rehabilitation training program residents. ${ }^{26}$ Attendings found EPAs feasible and generally reported satisfaction with EPAs as a way of providing feedback to residents. Feedback also suggested changes that could be made to improve future implementation, which included a more tailored entrustment scale for this practice area of medicine. ${ }^{26}$

\section{Gaps in knowledge and future directions for EPAs}

Two articles relating to gaps in knowledge and future direction for EPAs were identified for inclusion. Table 3 summarises the gaps in knowledge and future recommendations for EPAs. Although commentary in all articles included in this review discussed gaps in knowledge and the future direction and recommendations for EPAs in health professional education, a systematic review of EPAs in medical education and a scoping review for various health disciplines highlighted this theme as a main discussion point. ${ }^{4,32} \mathrm{O}^{\prime}$ Dowd and colleagues included 49 articles in a systematic review of EPAs in medical education including 39 articles on development of EPAs, and twelve relating to EPA implementation and/or evaluation (two studies are included in both categories). ${ }^{4}$ The authors highlight that there is a strong focus on EPA development, however, EPA implementation is also a critical part of the EPA process and currently this area of research is lacking. The authors recommend further data needs to be collected on validity, feasibility and utility of EPAs as an assessment tool for trainees. ${ }^{4}$

Shorey and colleagues conducted a scoping review for EPAs in health care education which included 80 articles. ${ }^{32}$ The article types included narrative articles $(n=13)$, research reports $(n=40)$, perspective papers $(n=10)$, commentaries $(n=11)$, an editorial $(n=1)$ and summit reports $(n=5)$. A thematic analysis revealed the following main themes: development of EPAs, evaluation of EPAs, entrustment factors and future direction and recommendations for EPAs. ${ }^{32}$ The authors concluded that the recent literature principally report the development and implementation of EPAs in various health disciplines. Supporting the conclusion reached by O'Dowd and colleagues, this review also highlights quality evidence-based research on the effectiveness and validity of EPAs as an education tool on a world-wide scale is lacking. ${ }^{4,32}$

\section{DISCUSSION}

The findings from this review add to the literature by describing how EPAs are currently utilised in medicine and nursing education with a focus on pharmacy education. This review highlights key considerations in the development of EPA frameworks, implementation, evaluation and future directives for EPAs.

Varied methods of development and validation of EPAs were reported with some commonality in the themes. Nursing and pharmacy health disciplines tended to follow the approach used by medical education in the development of EPAs, however, individualising the EPAs to their local setting and needs. Development of EPA frameworks for the workplace are often modelled on medical education, which link the educational context into the practice setting. ${ }^{33}$ Currently, there is no standardised approach to the development of EPAs. The use of standardised frameworks could improve the development process of EPAs and this has been acknowledged as a future focus for researchers. ${ }^{4,32} \mathrm{~A}$ suggested template by O'Dowd and colleagues, follows three steps: initial development, expansion and validation. ${ }^{4}$

Among the articles reviewed for EPA framework development, medical and pharmacy educators recognised the importance of mapping development of EPAs to the University's curriculum and any existing competency frameworks to translate educational theory into clinical practice. ${ }^{17,18,21}$ Kanmaz and colleagues described how an EPA task force successfully mapped all 15 core EPA statements developed by the AACP for pharmacy graduates in 2017 to the five educational guidance documents that govern the PharmD curriculum. ${ }^{21,34-37}$ This demonstrates the connection between curriculum design and assessment of student learning. ${ }^{21}$

During the EPA framework development stage, the QUEPA tool or EQual rubric can be applied to assess the quality of EPAs. ${ }^{4,89}$ Applying these validation tools when developing an EPA framework ensures the EPAs are of high quality and structure for the workplace and as an educational tool that assists the learner. No articles included in this review favoured or prioritised the use of either the EQual rubric or the QUEPA tool. Further, no other methods or tools for development of EPAs were identified, therefore the most effective method of developing high-quality EPAs could not be established.

The systematic review by O'Dowd and colleagues acknowledges the absence of a standardised approach when developing an EPA framework and highlights that this should be a priority area for future activity. ${ }^{4}$ To assist in 
successful implementation of EPAs, it is recommended to establish a uniform approach to the development of an EPA framework. ${ }^{4}$ A uniform approach can provide guidance for future researchers and increase the possibility of EPAs being a valid and effective learning tool for students in clinical practice. ${ }^{4}$

Following the EPA development process, implementation and evaluation of the EPAs is necessary to ensure the EPAs are suitable for workplace learning. No standardised approach or method to guide implementation and evaluation of EPAs has been identified in the literature. ${ }^{4,32}$ Currently, there are also limited studies that evaluate the feasibility of EPAs as an education tool once introduced to the workplace. ${ }^{26,31}$ In this review, documented methods to evaluate EPAs in the workplace included focus groups and surveys. ${ }^{24,25,28}$ This review found that successful implementation of EPAs may be underpinned by a rigorous and methodical approach in the development stage. Many authors reported challenges with implementation; until a set of standards to guide EPA development have been established, high quality evidence-based evaluation of EPA implementation may be limited. This is supported by the systematic review by O'Dowd, which discusses multiple approaches to implement and evaluate EPAs, suggesting a lack of knowledge and agreement on best practice implementation. ${ }^{4}$

This review found pharmacy educators are following the strategies used by medical educators in the development of EPAs including focusing on development of EPA statements, linking EPA statements to accreditation requirements, and validation of EPA tools. ${ }^{10} \mathrm{We}$ recommend a standardised approach to developing EPAs in health education be established including use of published frameworks. This could include using the QUEPA tool or EQual rubric validation tool during the development of EPAs. ${ }^{8,9}$

Accreditation programs internationally are adopting EPAs into their pharmacy education standards. ${ }^{36,38}$ This review provides additional guidance to accreditation bodies about ongoing development of EPAs and strategies for implementation and evaluation. Based on this review we recommend pharmacy educators involve key stakeholders in the development of EPAs. Having stakeholder involvement and feedback in the developmental process may assist in the implementation and acceptability of EPAs in the workplace.

Literature describing implementation and evaluation of pharmacy specific EPAs is scarce, reflecting the current situation in medical education. ${ }^{4}$ Based on our findings from this review, we recommend that focusing on implementation and evaluation of EPAs in addition to development of EPAs is crucial. Future directions for EPAs must include evaluating the feasibility and utility of EPAs in the workplace to understand whether EPAs are the most appropriate educative tool to support learner progression and skill development.

\section{CONCLUSION}

A standardised approach to development of EPA frameworks for medical, nursing and pharmacy disciplines has yet to be established. Implementation and evaluation of EPAs as an educational tool in the practice setting is also inconsistent and lacking in the literature. An opportunity exists to further establish the development, implementation and evaluation of EPAs for clinical education. EPAs are relatively new in pharmacy practice settings and much can be learned from other health professions to ensure successful translation of EPAs into pharmacy education.

\section{ACKNOWLEDGEMENTS}

The authors wish to acknowledge Mina Nichols-Boyd for assisting with the database review and Julian Lindsay and Michelle Vienet for their assistance in editing the manuscript.

\section{REFERENCES}

1. ten Cate O, Scheele F. Competency-based postgraduate training: can we bridge the gap between theory and clinical practice? Acad Med. 2007;82(6):542-547.

2. van Loon KA, Driessen EW, Teunissen PW, Scheele F. Experiences with EPAs, potential benefits and pitfalls. Med Teach. 2014;36(8):698-702.

3. ten Cate O. Nuts and bolts of entrustable professional activities. J Grad Med Educ. 2013;5(1):157-158.

4. O'Dowd E, Lydon S, O'Connor P, Madden C, Byrne D. A systematic review of 7 years of research on entrustable professional activities in graduate medical education, 2011-2018. Med Educ. 2019;53(3):234-249.

5. Englander R, Carraccio C. From Theory to Practice: Making Entrustable Professional Activities Come to Life in the Context of Milestones. Acad Med. 2014;89(10):1321-1323.

6. ten Cate O, Young JQ. The patient handover as an entrustable professional activity: adding meaning in teaching and practice. BMJ Qual Saf. 2012;21 Suppl 1:19-12.

7. O'Dowd E, Lydon S, O'Connor P, Boland J, Offiah G, Byrne D. The development of a framework of entrustable professional activities for the intern year in Ireland. BMC Med Educ. 2020;20(1):Article 273.

8. Taylor DR, Park YS, Egan R, et al. EQual, a Novel Rubric to Evaluate Entrustable Professional Activities for Quality and Structure. Acad Med. 2017;92:S110-s117.

9. Post JA, Wittich CM, Thomas KG, et al. Rating the quality of entrustable professional activities: content validation and associations with the clinical context. J Gen Intern Med. 2016;31(5):518-523. 
10. Sjoquist LK, Bush AA, Marciniak MW, Pinelli NR. An exploration of preceptor-provided written feedback on entrustable professional activities during early practice experiences. Am J Pharm Educ. 2021;85(3):Article 8091.

11. Haines ST, Pittenger AL, Stolte SK, et al. Core entrustable professional activities for new pharmacy graduates. Am J Pharm Educ. 2017;81(1):Article S2.

12. Rhodes LA, Marciniak MW, McLaughlin J, Melendez CR, Leadon KI, Pinelli NR. Exploratory Analysis of Entrustable Professional Activities as a Performance Measure During Early Pharmacy Practice Experiences. Am J Pharm Educ. 2019;83(2):Article 6517.

13. McArthur A, Klugárová J, Yan H, Florescu S. Innovations in the systematic review of text and opinion. Int J Evid Based Healthc. 2015;13(3):188-195.

14. Aromataris E, Fernandez R, Godfrey CM, Holly C, Khalil H, Tungpunkom P. Summarizing systematic reviews: methodological development, conduct and reporting of an umbrella review approach. Int $J$ Evid Based Healthc. 2015;13(3):132-140.

15. CASP Qualitative Checklist. Critical Appraisal Skills Programme 2018. https://casp-uk.net/casp-toolschecklists/. Accessed December 10, 2021.

16. $\quad$ Ferrari R. Writing narrative style literature reviews. Medical Writ. 2015;24(4):230-235.

17. Pittenger AL, Chapman SA, Frail CK, Moon JY, Undeberg MR, Orzoff JH. Entrustable Professional Activities for Pharmacy Practice. Am J Pharm Educ. 2016;80(4):Article 57.

18. Haines ST, Pittenger A, Plaza C. Describing entrustable professional activities is merely the first step. Am J Pharm Educ. 2017;81(1):Article 18.

19. Haines ST, Pittenger AL, Gleason BL, Medina MS, Neely S. Validation of the entrustable professional activities for new pharmacy graduates. Am J Health Syst Pharm. 2018;75(23):1922-1929.

20. Meyer EG, Taylor DR, Uijtdehaage S, Durning SJ. EQual Rubric Evaluation of the Association of American Medical Colleges' Core Entrustable Professional Activities for Entering Residency. Acad Med. 2020;95(11):1755-1762.

21. Kanmaz TJ, Culhane NS, Berenbrok LA, et al. A curriculum crosswalk of the core entrustable professional activities for new pharmacy graduates. Am J Pharm Educ. 2020;84(11):Article 8077.

22. Bonnie LHA, Visser MRM, Bont J, Kramer AWM, van Dijk N. Trainers' and trainees' expectations of entrustable professional activities (EPAs) in a primary care training programme. Educ Prim Care. 2019;30(1):13-21.

23. Pittenger AL, Gleason BL, Haines ST, Neely S, Medina MS. Pharmacy student perceptions of the entrustable professional activities. Am J Pharm Educ. 2019;83(9):Article 7274.

24. Martin L, Sibbald M, Brandt Vegas D, Russell D, Govaerts M. The impact of entrustment assessments on feedback and learning: Trainee perspectives. Med Educ. 2020;54(4):328-336.

25. Lau ST, Ang E, Samarasekera DD, Shorey S. Evaluation of an undergraduate nursing entrustable professional activities framework: an exploratory qualitative research. Nurse Educ Today. 2020;87:104343.

26. Baer HR, Gilbert AR, Forster JE, Ketchum NC, Mallow M, Nguyen VQC. Use of the electrodiagnostic entrustable professional activity for competency assessment in physical medicine and rehabilitation training programs. Am J Phys Med Rehabil. 2020;99(1):81-85.

27. Westein MPD, de Vries H, Floor A, Koster AS, Buurma H. Development of a postgraduate community pharmacist specialization program using canmeds competencies, and entrustable professional activities. Am J Pharm Educ. 2019;83(6):Article 6863.

28. Jarrett JB, Antoun J, Hasnain M. Entrustable professional activity utilization: a cera study of family medicine residency program directors. Fam Med. 2019;51(6):471-476.

29. Jarrett JB, Berenbrok LA, Goliak KL, Meyer SM, Shaughnessy AF. Entrustable professional activities as a novel framework for pharmacy education. Am J Pharm Educ. 2018;82(5):Article 6256.

30. ten Cate O, Graafmans L, Posthumus I, Welink L, van Dijk M. The EPA-based Utrecht undergraduate clinical curriculum: Development and implementation. Med Teach. 2018;40(5):506-513.

31. Hauer KE, Soni K, Cornett P, et al. Developing entrustable professional activities as the basis for assessment of competence in an internal medicine residency: a feasibility study. J Gen Intern Med. 2013;28(8):11101114.

32. Shorey S, Lau TC, Lau ST, Ang E. Entrustable professional activities in health care education: a scoping review. Med Educ. 2019;53(8):766-777.

33. Mulder H, Ten Cate O, Daalder R, Berkvens J. Building a competency-based workplace curriculum around entrustable professional activities: the case of physician assistant training. Med Teach. 2010;32(10):e453-459.

34. Medina MS, Plaza CM, Stowe CD, et al. Center for the Advancement of Pharmacy Education 2013 Educational Outcomes. Am J Pharm Educ. 2013;77(8):Article 162. 
35. Catizone A. NAPLEX Competency Statements, National Association of Boards of Pharmacy. https://nabp.pharmacy/naplex-competency-statements/. Accessed December 10, 2021.

36. Accreditation Council for Pharmacy Education. Accreditation Standards and Key Elements for the Professional Program in Pharmacy Leading to the Doctor of Pharmacy Degree ("Standards 2016"). Published February 2015. https://www.acpe-accredit.org/pdf/Standards2016FINAL.pdf. Accessed December 10, 2021.

37. Joint Commission of Pharmacy Practitioners. The Pharmacists' Patient Care Process. https://jcpp.net/wpcontent/uploads/2016/03/PatientCareProcess-with-supporting-organizations.pdf. Accessed December 10, 2021.

38. Australian Pharmacy Council. Accreditation Standards for Pharmacy Programs in Australia and New Zealand. Published January 2020. https://www.pharmacycouncil.org.au/resources/pharmacy-program-standards/. Accessed December 10, 2021.

Figure 1. Study Design Flow Chart

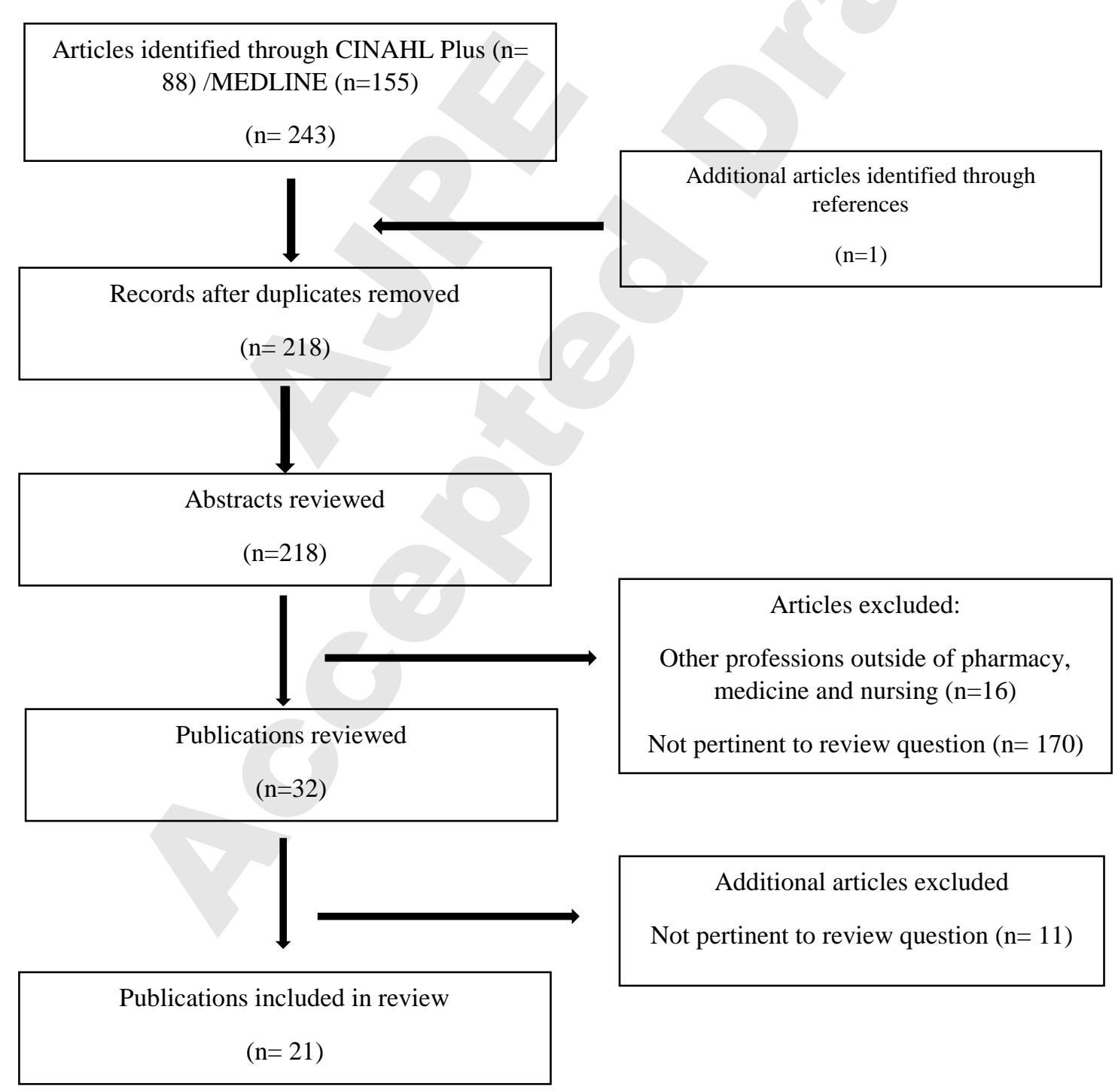


Table 1. Finding from a Review of the Literature on Frameworks for the Development of EPAs

\begin{tabular}{|c|c|c|c|c|}
\hline Primary Author (Year) & Profession & Evaluation Method (s) & $\begin{array}{l}\text { Study Sample (Response Rate } \\
\% \text { ) }\end{array}$ & Findings \\
\hline Taylor $(2017)^{8}$ & Medicine & $\begin{array}{l}\text { Generalizability study to } \\
\text { evaluate overall reliability of the } \\
\text { EQual rubric }\end{array}$ & N/A (descriptive) & $\begin{array}{l}\text { EQual rubric can reliably } \\
\text { measure EPA quality and } \\
\text { structure and has potential for } \\
\text { use in validation for EPA } \\
\text { development }\end{array}$ \\
\hline Bonnie $(2019)^{22}$ & Medicine & $\begin{array}{l}\text { Exploratory qualitative study } \\
\text { using focus group interviews }\end{array}$ & $49(100)$ & $\begin{array}{l}\text { Explored and reported the } \\
\text { expectations about EPAs for } \\
\text { trainers and trainees. }\end{array}$ \\
\hline Meyer $(2020)^{20}$ & Medicine & EQual rubric questionnaire & $10(60)$ & $\begin{array}{l}9 \text { of the } 13 \text { EPAs overall score } \\
\text { was above the cut-off score for } \\
\text { validation }\end{array}$ \\
\hline Pittenger (2016) ${ }^{17}$ & Pharmacy & N/A (descriptive) & N/A (descriptive) & $\begin{array}{l}\text { An EPA framework must be } \\
\text { based on sound educational } \\
\text { theory to fit the pharmacy } \\
\text { practice context }\end{array}$ \\
\hline Haines $(2017)^{18}$ & Pharmacy & N/A (descriptive) & N/A (descriptive) & $\begin{array}{l}\text { Describing EPAs is the first step } \\
\text { in the process }\end{array}$ \\
\hline Haines $(2018)^{19}$ & Pharmacy & $\begin{array}{l}\text { Questionnaire for pharmacists } \\
\text { based on the validated QUEPA } \\
\text { tool }\end{array}$ & $137(52)$ & $\begin{array}{l}\text { The core EPAs developed for } \\
\text { American Association of } \\
\text { Colleges of Pharmacy have face } \\
\text { validity and pertinent to } \\
\text { pharmacy practice }\end{array}$ \\
\hline Pittenger $(2019)^{23}$ & Pharmacy & $\begin{array}{l}\text { Questionnaire for pharmacy } \\
\text { students based on the validated } \\
\text { QUEPA tool }\end{array}$ & $423(\mathrm{NR})$ & $\begin{array}{l}\text { The core EPA statements were } \\
\text { consistently rated as relevant by } \\
\text { pharmacy students for pharmacy } \\
\text { practice }\end{array}$ \\
\hline Kanmaz $(2020)^{21}$ & Pharmacy & N/A (descriptive) & N/A (descriptive) & $\begin{array}{l}\text { Curriculum crosswalk for core } \\
\text { EPAs for new pharmacy } \\
\text { graduates }\end{array}$ \\
\hline
\end{tabular}

$\mathrm{NR}=$ Not reported 
Table 2. Finding from a Review of the Literature on Implementation and Evaluation of EPA for Workplace Learning

\begin{tabular}{|c|c|c|c|c|}
\hline Primary Author (Year) & Profession & Evaluation Method (s) & $\begin{array}{l}\text { Study Sample (Response Rate } \\
\% \text { ) }\end{array}$ & Findings \\
\hline Hauer $(2013)^{31}$ & Medicine & surveys & $28(65), 32(74)$ & $\begin{array}{l}\text { Survey results showed that most } \\
\text { agreed the piloted EPAs } \\
\text { facilitated useful feedback and } \\
\text { discussion and was feasible in } \\
\text { the practice setting }\end{array}$ \\
\hline Van Loon $(2014)^{2}$ & Medicine & N/A (descriptive) & N/A (descriptive) & $\begin{array}{l}\text { The authors identify two main } \\
\text { barriers that may result in } \\
\text { unsuccessful implementation: } \\
\text { EPAs being too detailed and the } \\
\text { need for workplaces to be } \\
\text { flexible. }\end{array}$ \\
\hline ten Cate $(2018)^{30}$ & Medicine & N/A (descriptive) & N/A (descriptive) & $\begin{array}{l}\text { Describes the development of a } \\
\text { clinical workplace curriculum } \\
\text { with an EPA structure including } \\
\text { the use of an electronic portfolio } \\
\text { system. }\end{array}$ \\
\hline Jarrett $(2019)^{28}$ & Medicine & Cross-sectional survey & $267(53)$ & $\begin{array}{l}\text { EPAs are recognised by family } \\
\text { medicine residency programs, } \\
\text { but the EPA assessment } \\
\text { framework is under utilised }\end{array}$ \\
\hline $\operatorname{Martin}(2020)^{24}$ & Medicine & $\begin{array}{l}\text { Exploratory qualitative study } \\
\text { using focus group interviews }\end{array}$ & $17(100)$ & $\begin{array}{l}\text { Use of entrustment as an } \\
\text { assessment outcome may have } \\
\text { an impact on the medical } \\
\text { trainees' motivation and feelings } \\
\text { of self-efficacy }\end{array}$ \\
\hline Lau $(2020)^{25}$ & Nursing & Exploratory qualitative study & $44(100)$ & Describes the perceptions and \\
\hline
\end{tabular}


using focus group interviews

Jarrett $(2018)^{29}$

Rhodes (2019) ${ }^{12}$

Westein (2019) ${ }^{27}$

Sjoquist (2021) $)^{10}$
Pharmacy

Pharmacy

Pharmacy

Pharmacy
N/A (descriptive review)

Student-self and preceptor-

student evaluations of EPA level

N/A (descriptive)

Retrospective review
N/A (descriptive)

N/A (descriptive)

N/A (descriptive) experiences of using a new EPA framework in nursing students,

hospital and university clinical instructors

A review about practical

understanding of EPAs in

pharmacy education and

implementation in pharmacy

curriculum

Increase in pharmacy students'

performance overtime (EPA

level increased)

Describes the design of a post-

graduate competency-based

curriculum

The value of pharmacist

preceptors providing feedback

to students about their EPA

performance can provide insight

into students' progression 
Table 3. Identified Gaps in Knowledge and Future Recommendations for EPAs

\section{Identified Gap in Knowledge}

Standardised approach to developing EPA

EPA implementation

EPA evaluation
Recommendation

Best practice guidelines for EPA development should be established

A focus on EPA implementation to ensure they are used for their intended purpose

Evaluating the feasibility and utility of EPAs in the workplace setting as an assessment tool for trainees 